\title{
Estimation of growth in solid state fermentation: A review
}

\author{
Musaalbakri Abdul Manan ${ }^{1,2}$ and Colin Webb ${ }^{2^{*}}$ \\ ${ }^{1}$ Enzyme and Fermentation Technology Programme, Biotechnology \& Nanotechnology Research Centre, Malaysian \\ Agricultural Research and Development Institute, Persiaran MARDI-UPM, 43400 Serdang, Selangor, Malaysia. \\ ${ }^{2}$ Satake Centre for Grain Process Engineering, School of Chemical Engineering and Analytical Science, Faculty of \\ Engineering and Physical Sciences, University of Manchester, United Kingdom. \\ Email: colin.webb@machester.ac.uk
}

Received 3 November 2016; Received in revised form 29 May 2017; Accepted 30 May 2017

\begin{abstract}
Carleysmith and Fox (1984) stated "without doubt, the single most vital yet most problematical value sought during fermentation is biomass estimation". Achieving a positive result in determining biomass remains a major challenge in solid state fermentation (SSF). Fungi are well-characterised microorganisms and are widely used in SSF due to their ability to colonise and penetrate into the solid substrate. The compressed structure of the mycelia and the solid substrate does not allow a complete recovery of the biomass, which may not be insurmountable. Since the use of a direct technique such as the dry weight method is impractical, the use of an indirect estimation technique is the only alternative. This review examines strategies that have been used to estimate biomass in SSF. Many promising indirect estimation techniques are available, which can be classified into six categories as follows; (i) measuring cell components not present in the substrate; (ii) measuring biomass component present in both substrate and biomass; (iii) measuring other secondary metabolites; (iv) measuring metabolic activity; (v) measuring images from direct microscopic observation and (vi) measuring biomass from the substrate matrix. New potential technique and future directions are also discussed in this review. Although significant advances have been made with the availability of various techniques; however, progress has been very unsatisfactory. The evaluation of microbial growth in SSF may sometimes become laborious, impractical and inaccurate. Essentially, this remains another critical issue for monitoring growth. The information of the profile of fungal biomass growth throughout any SSF process constitutes an essential parameter in estimation of kinetic variables and subsequently, scale-up of the process.
\end{abstract}

Keywords: Biomass estimation, fungal growth, solid state fermentation, filamentous fungi, solid substrate

\section{INTRODUCTION}

Solid state fermentation (SSF) has been defined in many ways. Many researchers in the field have introduced their own ways to define SSF. For example, Pandey et al (2000) defined SSF as the cultivation of microorganisms on moist solid supports, either on inert carriers or on insoluble substrates that can also be used as carbon and energy source. Mitchell et al. (2000) described SSF as any process in which substrates in a solid particulate state are utilised, while Viniegra-Gonzalez (1997) defined SSF as a microbial process occurring mostly on the surface of solid materials that have the property to absorb or contain water, with or without soluble nutrients. According to Rahardjo et al. (2006), SSF is the growth of microorganisms on moistened solid substrate, in which enough moisture is present to maintain microbial growth and metabolism, but where there is no free-moving water and air is the continuous phase. Rosales et al. (2007) gave a simple definition of SSF where the growth of microorganisms is on solid or semisolid substrates or support. In the latest definition, Mitchell et al. (2011) defined SSF as a process that involves the growth of microorganisms on moist particles of solid materials in beds in which the spaces between the particles are filled with a continuous gas phase. Whatever the definition, we can understand that SSF is referring to the microbial fermentation, which takes place in the absence or near absence of free water, thus being close to the natural environment to which the selected microorganisms, especially fungi, are naturally adapted.

SSF processes are clearly different from submerged fermentation (SmF). In most cases, it is soluble substrate supported on a solid insoluble matrix in an environment of low moisture content. In SSF, estimation of biomass presents difficulties as generally the fungal mycelium penetrates deep and remains attached with the solid substrate particles. The advantage of SSF comes from its 
simplicity and its closeness to the natural habitat of many microorganisms. Professor A.P.J. Trinci (Pandey et al., 2008) used the now frequently quoted phrase "God did not create filamentous fungi to grow in a fermenter". He claimed that $\mathrm{SmF}$ is an artificial condition for filamentous fungi because they live in nature in a solid state (Pandey et al., 2008). Most microorganisms, especially filamentous fungi and many actinomycetes, primarily live and grow in nature in SSF conditions (Carlile and Watkinson, 1994). More than $98 \%$ of isolates from marine environment have been obtained from the underwater surfaces of solid substrates and less than $1 \%$ of all known fungi have been found in marine habitats (Kelecom, 2002). The morphology factor of the microorganisms plays an important role since it can affect many aspects of the process. Through modern biotechnology, there are new initiatives to improve and enhance the productivity of SSF (Dalsenter et al., 2005). Each microorganisms, solid substrate, biomass estimation and bioreactor system plays a major role in the success of SSF.

\section{PROBLEM STATEMENT}

Previous studies suggest that traditional methods for SSF are all very similar and often involve low technology. As a consequence, it is difficult to measure growth and difficult to control the environment in such systems. Therefore, it is necessary to significantly improve the ability to measure and control the physical environment in SSF systems in order to be able to develop new and effective processes. To confirm the particular end product, it is necessary to use analytical methods to evaluate the fermentation process. In contrast to conventional fermentation processes (e.g. SmF), SSF does not allow for accurate biomass estimation. Attempts to estimate biomass have been made using many indirect techniques. For example, in the case of bacteria, ATP or DNA can be extracted and measured or, in the case of fungi, enzyme activity or glucosamine. However, none of these methods give satisfactory/conclusive results. The main disadvantage of most indirect techniques is that they are off-line, usually apply under a limited range of conditions and are labour intensive. By contrast, on-line techniques that measure oxygen uptake rate (OUR), carbon dioxide evolution rate (CER) and heat evolution rate are the most likely to meet with success.

From the literature, it is clearly demonstrated that studying microorganisms in controlled, well-phased cultures is of great importance. Above all, studying the early developments of the culture is particularly important because it is this phase, together with the physiological state of the microorganism, that determines the later stages of development (Desgranges et al., 1993). Measuring growth through a direct or an indirect technique is also important to provide a better understanding of process control and also to give an idea regarding the productivity of a cell culture (Borzani, 2000) nor to determine the effectiveness of a biotechnological process (Kiviharju et al., 2008; Singh et al., 1994; Sonnleitner et al., 1992). Normally, estimation of organic matter loss, dry weight, spores count and glucosamine content are made by taking samples intermittently and carrying out laboratory analysis. Organic matter loss and dry weight reduction were successfully proven for biomass estimation. However, these techniques were only satisfactory in laboratory study and did not permit estimation in large scale SSF. Biomass estimation is of fundamental importance in many microbial fermentation processes (Zwietering et al., 1990). However, this estimation is very difficult to make when solid substrate particles are present and bind to the cells. This review examines and evaluates about six (6) common techniques that have been used to estimate biomass in SSF (or sometimes in SmF involves solid particles).

\section{ESTIMATION OF GROWTH IN SOLID STATE FERMENTATION}

It is difficult to estimate biomass in SSF directly because it is very difficult to separate the microorganisms and the solid particles. This is more the case for fermentations involving filamentous fungi because fungal mycelium penetrates deeply into the substrate and becomes inextricably entangled within the solids. For this reason, it is better to use indirect methodologies for biomass estimation and having information about the cell biomass in such systems is very important. Chattaway et al. (1992) state "in the case of biomass estimation, elemental balances are useful either for obtaining on-line estimates or for calculating biomass off-line, when direct measurement is difficult, during fermentations on solidcontaining media".

Although there are a large number of studies on biomass estimation in SSF, the available methods do not perform well. There are operational and sample preparation difficulties around these existing methods. For example, dry weigh measurements (including both cells and the solid particles), are used to estimate cell biomass concentration, resulting in accurate data. A range of indirect methods can be used to estimate biomass, which can be classified into six categories:

1. Measuring cell components not present in the substrate

2. Measuring biomass component present in both substrate and biomass

3. Measuring other secondary metabolites

4. Measuring metabolic activity

5. Measuring images from direct microscopic observation

6. Measuring biomass from the substrate matrix

\section{Measuring cell components not present in the substrate}

Cell components (which are products of microbial activity) can be measured to estimate the growth of biomass. To do this, it is necessary to identify and measure components of the cell or mycelium, which are not normally present in the solid substrate. Cell components which can be measured include: glucosamine (Swift, 
1973; Sparringa and Owens, 1999), chitin or ergosterol (Feng et al., 2005), total sugar, DNA assay (nucleic acids) (Hashimoto et al., 1983; Solomon et al., 1983), ATP (Thierry and Chicheportiche, 1988), proteins (Raimbault and Alazard, 1980; Abd-Aziz et al., 2008), enzymes and others secondary metabolites. The most popular methods involve glucosamine estimation and profile production of enzymes (Ramesh et al., 1996). However, identifying cell components especially glucosamine, DNA and ergosterol is difficult and time-consuming due to tedious extraction procedures. For example, sample preparation for glucosamine and ergosterol measurement can take more than $24 \mathrm{~h}$ to complete. Measuring enzymatic activity or other secondary metabolites could be a reliable method for biomass estimation (Mitchell, 1992; Raimbault, 1997). A more practical logistic model developed by Ramesh et al. (1996) describes a-amylase and protease production, which are two non-growth associated enzymes produced by Bacillus licheniformis M27. However, it is not easy to perform sample preparation for the analytical assay.

\section{Measuring biomass components present in both substrate and biomass}

Protein content is related to cell biomass and is easy to measure when microorganisms are grown alongside nonprotein solid substrates. Significant amounts of protein are usually found in solid materials. The microorganism will therefore hydrolyse the substrate protein and produce biomass protein. Therefore, it can be difficult to tell the difference between protein from the cells and solid substrate protein. Measurements can wrongly be taken of total protein from both cells and solids. This biomass measurement technique is only reliable if solid substrate has no protein. Recent works by Oto et al. (2012; 2013) and Oshita et al. (2011) resulted in a non-destructive and real-time estimation method for monitoring microbial contamination. The method used a UV-Vis reflectance spectrum to measure ATP and/or a plate count on the surface of pork meat.

\section{Measuring other secondary metabolites}

Microbial secondary metabolites are useful high value products because they undergo a large number of biological activities. Secondary metabolites produced by a SSF system such as penicillin, tetracyclin, cephalosporin, iturin $A$, cephamycin $C$, ergot, alkaloids, monacolin $\mathrm{K}$, lovastatin and many others could be used to indicate growth in SSF. After microbial growth has occurred, secondary metabolites are synthesized in a fermentation medium (Krishna, 2005; Takashi et al., 2009). Pandey et al. (2001) argue that secondary metabolites build up near the end of fermentation, known as the idiophase that follows the active growth phase called trophophase. Secondary metabolites produced in the idophase are independent of synthesised cell material and normal microorganism growth.

\section{Measuring metabolic activity}

During fermentation processes, carbon is aerobically transformed into biomass, primary or secondary metabolites, carbon dioxide and water (Cordova-Lopez et al., 1996). Growth happens because of the interactions of microorganisms and their environments. Besides product formation and nutrients consumed, other factors, which affect growth are: environmental conditions (oxygen and carbon dioxide level, temperature, pressure and $\mathrm{pH}$ ) (Carrizalez et al., 1981). Continuously on-line monitoring of microbial growth could be performed by indirect methods measuring:

- Oxygen consumed (Cooney et al., 1969; Sato et al., 1983; Saucedo-Castaneda et al., 1994; Ikasari and Mitchell, 1998);

- Carbon dioxide produced (Carrizalez et al., 1981; Saucedo-Castaneda et al., 1994; Marsh et al., 1998; Assi et al., 2009);

- Metabolic heat (Cooney et al., 1969; Ratkowsky et al., 1983; Sangsurasak and Mitchell, 1995; 1998; Dalsenter et al., 2005; Fanaei et al., 2009) and

- Pressure levels during fermentation (Auria et al., 1993; Auria and Revah, 1994 Auria et al., 1995 )

The advantage of using this method is that there are no tedious and time consuming sampling processes. It is assumed that total carbon dioxide produced is proportional to the cumulative cell concentration (Terebiznik and Pilosof, 1999). The metabolic state of culture is estimated from the respiratory quotient $(R Q)$. The $R Q$ value is found by using carbon evolution and oxygen consumption rates ( $R Q=C E R / O U R)$. This can give indication of how well the substrate is aerated as high $R Q$ values indicate fermentative metabolism (Mitchell et al., 2002). This could be applied to other biological systems where carbon dioxide is a growth product. Heat is also produced by microbial activity and so could be used to measure biomass. Another reported method shows that growth and pressure drop at the same rate across an aerated SSF fermentation bed (Auria et al., 1993; Auria and Revah, 1994 Auria et al., 1995). Once technology becomes more advanced over time, on-line microbial metabolism could be suitable for determining growth in aerobic SSF, by measuring rates of oxygen uptake, carbon dioxide evolve, heat evolution and pressure changes. Facilities could be expensive but useful for gaining information on microbial growth yet very accurate. These techniques are suited for use on-line and so are most likely to meet success in the future.

Metabolic respiratory (OUR, CER) and temperature profiles during SSF are linearly related with biomass synthesis in an aerobic fermentation. They are considered to be the most accurate for determination of growth of the microorganisms in SSF. The technique is also suitable for large scale SSF due to its advantages such as overcoming the sampling process, avoiding damage of mycelium and the on-line and fast delivery nature of the 
technique. OUR, CER and heat evolved are the most meaningful techniques to estimate biomass in SSF. The data obtained from OUR, CER and heat evolved allows the estimation of the kinetics of fungal growth. With the present advanced technology, solid state bioreactors should be designed with an on-line facility for monitoring of several parameters as well as studies that consider transport phenomena at micro-scale levels, primarily including heat and mass transfer in a system characterised by a gas-solid interface. Supervision is a higher-level automation, in which measurements are processed in real time to generate more useful information.

\section{Measuring images through direct microscopic observation}

Another method is image analysis through microscopic observation. This can be done using Scanning Electron Microscope or Confocal Microscopy. Growth patterns taken from digital image analysis (Yingyi et al., 2012; Barry and Williams, 2011; Feng et al., 2007; Couri et al., 2006) are interpreted by computer software, which calculates total length or volume mycelium growing in the SSF system (Raimbault, 1997). Osma et al. (2011) developed software using a Matlab platform to estimate fungal culture's occupied area and volume. This allows high-definition images from scanning electron and environmental scanning electron microscope to be analysed. To monitor the biomass growth of Aspergillus niger, Dutra et al. (2008) measured the hyphae area in an image from stereomicroscope Carl Zeiss STEMI 2000-CS and found a correlation with lipase activity.

Another technique uses confocal scanning laser microscopy to measure concentration of penetrative biomass during growth (Nopharatana et al., 2003a; 2003b). However, this technique is only suitable if artificial solid substrate is used. Miri et al. (2003) studied fungal hyphae's morphology and structure during SSF. They used manual image analysis after staining the sample with a fluorescent contrast agent. Afterwards, they used a fluorescence microscope to see the fibres. This method involves expensive equipment and specific software needs to be developed. With these above methods, there are disadvantages. Some need special processes with tedious procedures, the amount of sample needed varies and operator fatigue can decrease accuracy level. In all cases, the cells attach to the solid particles. Cells are scattered and not evenly distributed. Cell damages during sample processing are also high possibility. Despite clear developments in image analysis, predictive, easy to apply models have not been developed. Routine measurement of biomass using this method is not practical, despite great potential. Using haemocytometer under microscope to count spores or cells is usually a last resort.

\section{Measuring biomass from the solid matrix}

In recent times, direct evaluation of biomass using a membrane filter has become possible. This is because the whole fungal mycelium can be easily recovered by peeling it off the membrane and weighing it immediately after drying (Ooijkaas et al., 2000). However, this technique is only suited to small scale bioreactor or lab studies. Another disadvantage is that it is difficult for fungal mycelium to penetrate especially large and deep solid particles. Terebiznik and Pilosof (1999) grew Aspergillus oryzae NRRL 3458 in wheat bran and measured dry matter weight loss in terms of mycelia growth. Okazaki et al. (1980) used the mathematical model for estimating fungal growth in SSF. They estimated biomass growth from dry matter weight loss by incorporating with carbon dioxide evolution into a relationship. Wang et al. (2010) adapted the logistic model as originally proposed by Okazaki et al. (1980). They successfully applied a dry weight reduction ratio for $A$. oryzae fermentation using rapeseed meal.

\section{Other techniques}

Ramana Murthy et al. (1993) monitored biomass in SSF using light reflectance. They observed colour changes due to the growth of the fungus during SSF. They used CIE (Commission International de l'Eclairage) system based on the principles of additive colour mixing. The measurements taken were looked at against glucosamine concentration. The authors concluded that colour and glucosamine were closely linked. This technique for biomass estimation in SSF could be developed but no follow-up work has been done.

There is potential for using Biomass Monitor to measure radio-frequency dielectric properties (Aber Instruments Ltd, Science Park, Cefn Llan, Aberystwyth, Dyfed SY23 3DA, UK). The online method involves taking measurements of the dielectric permittivity at low radio frequencies; by using biomass probe (the Bugmeter) which has four terminal sensors. Computerised system measures the capacitance at $0.3 \mathrm{MHz}$ (in picofarads), which indicates of biomass. This technique was shown to measure biomass in SmF without presence of solid particles either using yeast, bacteria or even fungus (Harris and Kell, 1985; Harris et al., 1987).

Articles produced by Penaloza et al. (1991) and Davey et al. (1991); showed that the microbial biomass during SSF for tempe production could be estimated by the monitor measuring in capacitance (fungus Rhizopus oligosporus was used). It was found that this technique produced linearity during the growth phase, between the dielectric permittivity and the hyphae length (as determined microscopically). The finding was supported by other researchers (Fehrenbach et al., 1992) that biomass monitoring could be measured on-line by capacitance. According to Darvey et al. 1991, the biomass monitor provides a reliable, one of a kind, easy to reproduce and on-line measurement of biomass in SSF. Botella (2007) also suggested that this technique has potential to monitor on-line fungal growth in SSF. As with light reflectance technique, there is no work reported after year 1991. Therefore, this technique shows potential for further development. 
The online measurement of capacitance using the Biomass monitor technique seemed very promising but might not be approachable for SSF especially in large scale. However, it works excellently and should be explored further for fungal biomass estimation in largescale SmF involving solid substrate particles. The measurement procedures can be done on-line without involving tedious sampling processes, although they are more expensive. If properly calibrated and compensated, these devices may be useful to measure the capacitance in SSF and SmF.

There are disadvantages to most of the categories listed in Table 1. A common problem for indirect methods of biomass estimation is that the relationship between biomass and the factor measured can change over time. No methods currently involve calibration, which could better measure the relationship with biomass. It is necessary to have a direct measurement of the biomass through calibration methods.

\section{New potential technique}

In general, colour of the fermenting solid substrate changes during the course of the SSF due to the growth of the fungus. During the course of the investigation of fungal growth on solid substrate, it was found that the colour of the solid substrate became darker with progressive growth. If this colour changes could be quantitatively related to fungal growth, it might become a new technique for the estimation of fungal growth in SSF.

The theory of measuring colour changes in SSF by UV-Vis spectroscopy demonstrates that this colourimetric technique provides valuable information. The key finding is that the colourimetric technique demonstrated and provided information of higher quality than that obtained by visual observation or spores counting (Musaalbakri, 2014; Musaalbakri and Webb 2016). For the growth of Aspergillus awamori and Aspergillus oryzae on wheat bran, soybean hulls and rapeseed meal, it was confirmed that colour production was directly proportional to fungal growth. Colour from cell free extracts absorbs light in the region $260-300 \mathrm{~nm}$ that largely corresponds to pigments in the supernatant. Colour density measured for fungal SSF in cell free extracts can be determined quickly and accurately using absorbance measurement at the chosen wavelength of $300 \mathrm{~nm}$. The advantages of this method include the fact that the procedure is cheap, fast, objective, simple to carry out, non-destructive and no special or expensive reagents are required. Making cell free extracts from fermented fungal biomass was carried only using distilled water and was performed in less than $2 \mathrm{~h}$. Water was efficient in the recovery of colour. The results of this study indicated that the colourimetric technique could be used to monitor biomass growth in a SSF process and to correlate biomass growth and weight fungus, spores concentration, organic matter loss, glucosamine and enzyme activity. This colourimetric technique was also proved to be a feasible approach for fungal biomass estimation in SmF. This new approach is an important complementation to the existing techniques especially for basic studies.

Understanding the variations in biomass components and their interactions can enable development of new techniques for biomass estimation in SSF. Apart from being a potential technique to describe growth in fungal SSF, colour production measurement in fungi provides a very elegant technique to monitor the way fungi use their metabolism to survive and adapt to different environments. Overall, the estimation of colour density through UV-Vis spectrophotometry from SSF would be a favourable indirect method to describe the growth of fungi. A higher number of experiments and improvements on the colour changes technique in SSF using various microorganisms and solid substrates are needed to validate the technique. Further studies should be carried out to obtain more data to support the colourimetric technique using different fungi and bacteria, and also using different types of solid substrate whether in single form or mixed-solid substrate from different solid wastes.

\section{The future}

The promise of industrial biotechnology has been around since Chaim Weizmann developed the acetone-butanolethanol fermentation in the University of Manchester in 1917 and the prospects nowadays look brighter than ever. In the future, SSF may become more important as a technology to process alternative, bio-based feedstocks that will replace the declining petroleum resources. There will be efforts and ever-increasing pressure to move towards biorefineries for the production of industrial biochemicals (Mitchell et al., 2011). The large-scale cultivation of microorganisms will be an integral part of such biorefineries. Future biorefineries based on SSF aim to exploit the vast complexity of the technology to modify biomass produced by agriculture and food industry for valuable by-products through microbial bioconversion. This can be achieved since SSF technology offers the advantage and potential to minimise the addition of water and thus optimise process economics in biorefineries. On top of that, in order to meet the requirements of SSF as a potential technology, it is necessary to have effective methods to determine biomass growth for optimised performance. No method is ideally suited to all situations and hence the most appropriate method to a particular fermentation application must be chosen in each case based on the simplicity of the procedure, its cost and its accuracy.

\section{Concluding remarks}

Different techniques for biomass estimation are gathered, described and discussed. Several well-known indirect techniques to investigate biomass growth in simple petri dish and bioreactor cultures were reviewed. These were used to make biomass estimations, in order to carry out a critical informative comparison. Such techniques have the benefit of being practical, reliable and not too timeconsuming in estimating fungal growth. It is about time 
now for research to be carried out in biosensor technology to design special electrodes for on-line $\mathrm{pH}$ measurement in solid substrate with the presence of little amount of water. Biosensors are compact and highly specific analytical instruments that comprise biological sensing components such as tissues, cells, enzymes or antibodies. To the best our knowledge, this type of instruments has not be evaluated in SSF so far.

Table 1: Summary of the categories of methods used to estimate biomass in SSF.

\begin{tabular}{|c|c|}
\hline Category & Comments \\
\hline $\begin{array}{l}\text { Measuring cell } \\
\text { components that are } \\
\text { not present within the } \\
\text { solid substrate }\end{array}$ & $\begin{array}{l}\text { Most of the cell components are not in constant proportion of the cell mass } \\
\text { during all stages of development } \\
\text { Tedious extraction process, time-consuming } \\
\text { Expensive reagents/chemicals, strong chemicals, buffer preparation }\end{array}$ \\
\hline $\begin{array}{l}\text { Measuring biomass } \\
\text { components probably } \\
\text { present in both solid } \\
\text { substrate and biomass }\end{array}$ & $\begin{array}{l}\text { Difficult to differentiate biomass components coming from either cells or solids } \\
\text { - interference with a substrate rich in protein } \\
\text { Not accurate definition of biomass concentration } \\
\text { Involves tedious extraction process, time-consuming } \\
\text { Expensive reagents/chemicals/kits, buffer preparation }\end{array}$ \\
\hline $\begin{array}{l}\text { Measuring other } \\
\text { secondary metabolite }\end{array}$ & $\begin{array}{l}\text { Most of the cell components are not in a constant proportion of the cell mass } \\
\text { during all stages of development } \\
\text { Not always related to growth } \\
\text { Tedious extraction process, time-consuming, } \\
\text { Expensive reagents/chemicals, strong chemicals, buffer preparation }\end{array}$ \\
\hline $\begin{array}{l}\text { Measuring metabolic } \\
\text { activity }\end{array}$ & $\begin{array}{l}\text { The oxygen uptake rate (OUR), carbon dioxide evolution rate (CER) and } \\
\text { metabolic heat evolution rate techniques are the easiest to operate on-line } \\
\text { No regular sampling process } \\
\text { Shows a potential for further development } \\
\text { The metabolic production is proportional to biomass concentration but may } \\
\text { vary with time during the fermentation } \\
\text { Always related to growth } \\
\text { Requires expensive equipment and dedicated software } \\
\text { Requires frequent calibration }\end{array}$ \\
\hline $\begin{array}{l}\text { Measuring images } \\
\text { through direct } \\
\text { microscopic } \\
\text { observation }\end{array}$ & $\begin{array}{l}\text { Labour-intensive, time-consuming, cells adhering to solid surface causes } \\
\text { damage problems, requires considerable time } \\
\text { Microscope has a higher resolution than the conventional light microscope } \\
\text { Suitable if using an artificial solid media }\end{array}$ \\
\hline $\begin{array}{l}\text { Measuring biomass } \\
\text { from the solid matrix }\end{array}$ & $\begin{array}{l}\text { Adapted for fungi only } \\
\text { Suited only to a few cases, especially practical in lab scale studies } \\
\text { Complete separation is difficult }\end{array}$ \\
\hline
\end{tabular}

\section{ACKNOWLEDGEMENT}

This work was funded by Malaysian Agricultural Research and Development Institute (MARDI) and Government of Malaysia through the scheme's study leave.

\section{REFERENCES}

Abd-Aziz, S., Hung, M. A., Hassan, M. A., Karim, M. I. A. and Samat, N. (2008). Indirect method for quantification of cell biomass during solid state fermentation of palm kernel cake based on protein content. Asian Journal of Science Resources 1, 385393.

Assi, J. A., King, A. J. and Gheynst, J. V. (2009). $\mathrm{CO}_{2}$ evolution rate during solid-state fermentation for preparation of tomato pomace as poultry feed ingredient. International Journal of Agricultural and Biological Engineering 2(1), 28-32.

Auria, R., Ortiz, I., Villegas, E. and Revah, S. (1995). Influence of growth and high mold concentration on the pressure drop in solid state fermentations. Process Biochemistry 30(68), 751-756.

Auria, R. and Revah, S. (1994). Pressure drop as a method to evaluate mold growth in solid state 
fermenters. In: Advances in Bioprocess Engineering. Galido, E. and Ramirez, O. T. (eds.). Kluwer Academic Publisher, Dordrecht. pp. 289-294.

Auria, R., Morales, M., Villegas, E. and Revah, S. (1993). Influence of mold growth on the pressure drop in aerated solid state fermenters. Biotechnology and Bioengineering 41, 1007-1013.

Barry, D. J. and Williams, G. A. (2011). Microscopic characterisation of filamentous microbes: Towards fully automated morphological quantification through image analysis. Journal of Microscopy 244(1), 1-2.

Borzani, W. (2000). A weighing method to identify the microbial growth phases in solid-state fermentation tests. World Journal of Microbiology and Biotechnology 16(7), 601-605.

Botella, C. F. (2007). Particulate bioprocessing: A novel process strategy for biorefineries. PhD Thesis. The University of Manchester, United Kingdom.

Carlile, M. J. and Watkinson, S. C. (1994). The fungi. Academic Press, San Diego, California. pp. 55-62.

Carrizalez, V., Rodríguez, H. and Sardina, I. (1981). Determination of the specific growth of molds on semisolid cultures. Biotechnology and Bioengineering 23(2), 321-333.

Carleysmith, S. W. and Fox, R. L. (1984). Fermenter instrumentation and control. Advanced Biotechnological Processes. 4, 1-51.

Chattaway, T., Demain, A. L. and Stephanopoulos, G. (1992). Use of various measurements for biomass estimation. Biotechnology Progress 8(1), 81-84.

Cooney, C. L., Wang, D. I. C. and Mateles, R. I. (1969). Measurement of heat evolution and correlation with oxygen consumption during microbial growth. Biotechnology and Bioengineering 11(3), 269-281.

Couri, S., Merces, E. P., Neves, B. C. V. and Senna, L. F. (2006). Digital processing as a tool to monitor biomass growth in Aspergillus niger 3T5B8 solid-state fermentation: Preliminary results. Journal of Microscopy 224(3), 290-297.

Cordova-Lopez, J., Gutierrez-Rojas, M. Huerta, A. and Saucedo-Castaneda, G. (1996). Biomass estimation of Aspergillus niger growing on real and model supports in solid state fermentation. Biotechnology Techniques 10, 1-6.

Dalsenter, F. D. H., Viccini, G., Barga, M. C., Mitchell, D. A. and Krieger, N. (2005). A mathematical model describing the effect of temperature variations on the kinetics of microbial growth in solid-state culture. Process Biochemistry 40, 801-807.

Davey, C. L., Penaloza, W., Kell, D. B. and Hedger, J. N. (1991). Real-time monitoring of the accretion of Rhizopus oligosporus biomass during the solidsubstrate tempe fermentation. World Journal of Microbiology and Biotechnology 7, 248-259.

Desgranges, C., Vergoignan, C., Lereec, A., Riba, G. and Durand, A. (1993). Use of solid state fermentation to produce Beauveria bassiana for the biological control of European corn borer. Biotechnology Advances 11(3), 577-587.
Dutra, J. C. V., Terzi, S. C., Bevialaqua, J. V., Damaso, M. C. T., Couri, S., Langone, M. A. P. and Senna, L. F. (2008). Lipase production in solid-state fermentation monitoring biomass growth of Aspergillus niger using digital image processing. Applied Biochemical and Biotechnology 147, 63-75.

Fanaei, M. A. and Vaziri, B. M. (2009). Modelling of temperature gradients in packed-bed solid-state bioreactors. Chemical Engineering and Processing: Process Intensification 48, 446-451.

Fehrenbach, R., Comberbach, M. and Petre, J. 0. (1992). On-line biomass monitoring by capacitance measurement. Journal of Biotechnology 23, 303-314.

Feng, X. M., Olsson, J., Swanberg, M., Schnurer, J. and Ronnow, D. (2007). Image analysis for monitoring the barley tempeh fermentation process. Journal of Applied Microbiology 103(4), 1113-1121.

Feng, X. M., Eriksson, A. R. B. and Schnürer, J. (2005). Growth of lactic acid bacteria and Rhizopus oligosporus during barley tempeh fermentation. International Journal of Food Microbiology 104, 249256.

Harris, C. M., Todd, R. W., Bungard, S. J., Lovitt, R. W., Morris, J. G. and Kell, D. B. (1987). Dielectric permittivity of microbial suspensions at radio frequencies: A novel method for the real-time estimation of microbial biomass. Enzyme and Microbial Technology 9, 181-186.

Harris, C. M. and Kell, D. B. (1985). The estimation of microbial biomass. Biosensors 1, 17-84.

Hashimoto, H., Kikuchi, Y., Nogi, Y. and Fukasawa, T. (1983). Regulation of expression of the galactose gene cluster in Saccharomyces cereviasiae: Isolation and characterization of the regulatory gene GAL4. Molecular Genetics and Genomics 191(1), 31-38.

Ikasari, L. and Mitchell, D. A. (1998). Oxygen uptake rate kinetics during solid state fermentation with Rhizopus oligosporus. Biotechnology Techniques 12(2), 171-175.

Kelecom, A. (2002). Secondary metabolites from marine microorganism. Annals Academia Brazilian Sciences 74(1), 151-170.

Kiviharju, K., Salonen, K., Moilanen, U. and Eerikainen, T. (2008). Biomass measurement online: The performance of in situ measurements and software sensors. Journal of Industrial Microbiology and Biotechnology 35(7), 657-665.

Krishna, C. (2005). Solid-state fermentation system - An overview. Critical Reviews in Biotechnology 25, 1-30.

Marsh, A. J., Mitchell, D. A., Stuart, D. M. and Howes, T. (1998). $\mathrm{O}_{2}$ uptake during solid-state fermentation in a rotating drum bioreactor. Biotechnology Letters 20(6), 607-611.

Miri, T., Cox, P. W. and Fryer, P. J. (2003). In-situ visualization of hyphal structure and arrangement in mycoprotein pastes. Biotechnology Letters 25, 295300.

Mitchell, D. A., de Lima Luz, L. F. and Krieger, N. (2011). Bioreactors for solid-state fermentation. In: 
Comprehensive Biotechnology. Moo-Yong 2nd Edn. M. Elsevier, 2, 347-360.

Mitchell, D. A., Tongta, A., Stuart, D. M. and Krieger, N. (2002). The potential for establishment of axial temperature profiles during solid-state fermentation in rotating drum bioreactors. Biotechnology and Bioengineering 80(1), 114-122.

Mitchell, D. A., Berovic, M. and Krieger, N. (2000). Biochemical engineering of solid state bioprocessing. Advanced Biochemical Engineering Biotechnology 68, 61-138.

Mitchell, D. A. (1992). Growth patterns growth kinetics and the modeling of growth in solid state cultivation. In: Solid Substrate Cultivation. Doelle, H. W., Mitchell, D. A. and Rolz, C. E. (eds.). Elsevier Science Publishers, Amsterdam. pp 87-112.

Musaalbakri, A. M. (2014). Design aspects of solid state fermentation. PhD Thesis. University of Manchester, United Kingdom.

Musaalbakri, A. M. and Webb, C (2016). Extracted substrate colour as an indicator of fungal growth in solid state fermentation. Malaysian Journal of Microbiology 12(6) Special Issue, 445-449.

Nopharatana, M., Mitchell. D. A. and Howes, T. (2003a). Use of confocal scanning laser microscopy to measure the concentrations hyphae during growth of Rhizopus oligosporus on a solid surface. Biotechnology and Bioengineering 84(1), 71-77.

Nopharatana, M., Mitchell, D. A. and Howes, T. (2003b). Use of confocal microscopy to follow the development of penetrative hyphae during growth of Rhizopus oligosporus in an artificial solid-state fermentation system. Biotechnology and Bioengineering 81(4), 438-447.

Okazaki, N., Sugama, S. and Tanaka, T. (1980). Mathematical model for surface culture of koji mold. Journal of Fermentation Technology 58, 471-476.

Ooijkaas, L. P., Weber, F. J., Buitelaar, R. M., Tramper, J. and Rinzema, A. (2000). Defined media and innert support: Their potential as solid-state fermentation production systems. Trends in Biotechnology 18(8), 356-360.

Oshita, S., Al-Haq, M. I., Kawagishi, S., Makino, Y., Kawagoe, Y., Ye, X., Shinozaki, S. and Hiruma, N. (2011). Monitoring of ATP and viable cells on meat surface by UV-Vis reflectance spectrum analysis. Journal of Food Engineering 107(2), 262-267.

Osma, J. F., Toca-Herrera, J. L. and Rodriguez-Cauto, S. (2011). Environmental, scanning electron and optical microscope image analysis software for determining volume and occupied area of solid-state fermentation fungal cultures. Biotechnology Journal 6, 45-55.

Oto, N., Oshita, S., Makino, Y., Kawagoe, Y., Sugiyama, J. and Yoshimura, M. (2013). Nondestructive evaluation of ATP content and plate count on pork meat surface by fluorescence spectroscopy. Meat Science 93, 579-585.

Oto, N., Oshita, S., Kawagishi, S., Makino, Y., Kawagoe, Y., Al-Haq, M. I., Shinozaki, S. and
Hiruma, N. (2012). Non-destructive estimation of ATP contents and plate count on pork meat surface by UVvis reflectance spectrum analysis. Journal of Food Engineering 110(1), 9-17.

Pandey, A., Soccol, C. R. and Laroche, C. (2008). Part 1: General and fundamentals aspects of SSFIntroduction. In: Current Development in Solid-state Fermentation. Pandey, A., Soccol, C. R. and Laroche, C. (eds.). Springer Science+Business Media, LLC, New York. pp. 3-12.

Pandey, A., Soccol, C. R., Rodriguez-Leon, J. A. and Nigam, P. S. (2001). General considerations about solid-state fermentation processes. In: Solid-state Fermentation in Biotechnology - Fundamentals and Application. Pandey, A., Soccol, C. R., Rodguez-Leon, J. A. and Nigam, P. S. (eds.). Asiatech Publishers, Inc. New Delhi. pp. 8-17.

Pandey, A., Soccol, C. R. and Mitchell, D. A. (2000). New developments in solid state permentation. In: Processes and products. Process Biochemistry 35, 1153-1169.

Penaloza, W., Davey, C. L., Hedger, J. N. and Kell, D. B. (1991). Stimulation by potassium ions of the growth of Rhizopus oligosporus during liquid- and solidsubstrate fermentations. World Journal of Microbilogy and Biotechnology 7, 260-268.

Rahardjo, Y. S. P., Tramper, J. and Rinzema, A. (2006). Modeling conversion and transport phenomena in solid-state fermentation: A review and perspectives. Biotechnology Advance 24, 161-179.

Raimbault, M. (1997). General microbiological aspects of solid substrate fermentation. In: Raimbault, M., Soccol, C. R. and Chuzel, G. (eds.). Proceedings of the International Course on Solid State Fermentation, Curitiba, Brazil pp. 1-20.

Raimbault, M. and Alazard, D. (1980). Culture method to study fungal growth in solid fermentation. European Journal of Applied Microbiology and Biotechnology 9, 199-209.

Ramana Murthy, M. V., Thakur, M. S. and Karanth, N. G. (1993). Monitoring of biomass in solid state fermentation using light reflectance. Biosensors and Bioelectronics 8, 59-63.

Ramesh, M. V., Charyulu, C. L. N., Chand, N. and Lonsane, B. K. (1996). Non-growth associated production of enzymes in solid state fermentation system: Its mathematical description for two enzymes produced by Bacillus licheniforms M27. Bioprocess Engineering 15, 289-294.

Ratkowsky, D. A., Lowry, R. K., McMeekin, T. A., Stokes, A. N. and Chandler, R. E. (1983). Model for bacterial growth rate throughout the entire biokinetic temperature range. Journal of Bacteriology 154(3), 1222-1226.

Rosales, E., Couto, S. R. and Sanroman, M. A. (2007). Increased laccase production by Trametes hirsuta grown on ground orange peelings. Enzyme and Microbial Technology 40, 1286-1290.

Sangsurasak, P. and Mitchell, D. A. (1998). Validation of a model describing two-dimensional heat transfer 
during solid-state fermentation in packed bed bioreactors. Biotechnology and Bioengineering 60(6), 739-749.

Sangsurasak, P. and Mitcehll, D. A. (1995). Incorporation of death kinetics into a 2-dimensional dynamic heat transfer model for solid state fermentation. Journal of Chemical Technology and Biotechnology 64(3), 253-260.

Saucedo-Castaneda, G., Trejo-Hernandez, M. R., Lonsane, B. K., Navarro, J. M., Roussos, S., Dufour, D. and Raimbault, M. (1994). On-line automated monitoring and control systems for $\mathrm{CO}_{2}$ and $\mathrm{O}_{2}$ in aerobic and anaerobic solid-state fermentations. Process Biochemistry 29(1), 13-24.

Sato, K., Nagatani, M., Nakamuri, K. I. and Sato, S. (1983). Growth estimation of Candida lipolytica from oxygen uptake rate in a solid culture with forced aeration. Journal of Fermentation Technology 61(6), 623-629.

Singh, A., Kuhad, R. C., Sahai, V. and Gosh, P. (1994). Evaluation of biomass. Advance of Biochemical Engineering and Biotechnology 51, 47-70.

Solomon, G., Schiffenbauer, J., Keiser, H. D. and Diamond, B. (1983). Use of monoclonal antibodies to identify shared idiotypes on human antibodies to native DNA from patients with systemic lupus erythematosus. Proceedings of the National Academy of Sciences USA. 80(3), 850-854.

Sonnleitner, B., Locher, G. and Fiechter, A. (1992). Biomass determination. Journal of Biotechnology 25, 5-22.

Sparringa, R. A. and Owens, J. D. (1999). Glucosamine content of tempe mould Rhizopus oligosporous. International Journal of Food Microbiology 47, 153157.

Swift, M. J. (1973). The estimation of mycelial biomass by determination of the hexosamine content of wood tissue decayed by fungi. Soil Biology and Biochemistry 5, 321-332.

Takashi, A., Guan Yuan, J., Shinji, M., Mohammad Shahedur, R., Kasumasa, O. and Makoto, S. (2009). Solid state fermentation of lipopeptide antibiotic iturin A by using a novel solid state fermentation reactor system. Journal of Environmental Sciences S162S163.

Terebiznik, M. R. and Pilosof, A. M. R. (1999). Biomass estimation in solid state fermentation by modelling dry matter weight loss. Biotechnology Techniques 13, 215-219.

Thierry, A. and Chicheportiche, R. (1988). Use of ATP bioluminescence measurements for the estimation of biomass during biological humification. Applied Microbiology and Biotechnology 28(2), 199-202.

Viniegra-Gonzalez, G. (1997). Solid state fermentation: Definition, characteristics, limitations and monitoring. In: Advances in Solid State Fermentation. Roussos, S. Lonsane, B. K., Raimbault, M. and ViniegrazGonzalez, G. (eds.). Kluwer Acad. Publishers, Dordrecht. pp. 5-22.
Wang, R.-H, Shaarani, S. M., Godoy, L. C., Melikoglu, M., Vergara, C. S., Koutinas, A. and Webb, C. (2010). Bioconversion of rapeseed meal for the production of a generic microbial feedstock. Enzyme and Microbial Technology 47, 77-83.

Yingyi, D., Lan, W. and Hongzhang, C. (2012). Digital image analysis and fractal-based kinetic modelling for fungal biomass determination in solid-state fermentation. Biochemical Engineering Journal 67, 6067.

Zwietering, M. H., Jorgenberger, F., Rombouts, M. and Van, T. R. (1990). Modelling of the bacterial growth curve. Applied and Environmental Microbiology 56(6), 1875-1881. 